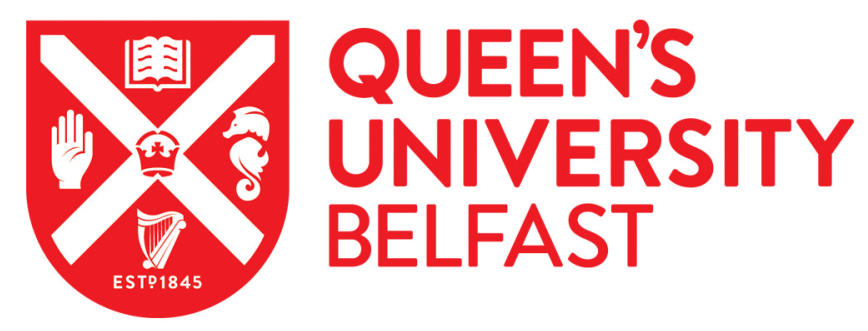

\title{
Treatment for erectile dysfunction among older men in Northern Ireland
}

Donnelly, D., Kearney, T., McCaughan, E., Downing, A., Weller, D., Glaser, A. W., \& Gavin, A. (2019).

Treatment for erectile dysfunction among older men in Northern Ireland. International Journal of Clinical Practice, 73(1), [e13259]. https://doi.org/10.1111/ijcp.13259

Published in:

International Journal of Clinical Practice

Document Version:

Peer reviewed version

Queen's University Belfast - Research Portal:

Link to publication record in Queen's University Belfast Research Portal

Publisher rights

(C) 2018 John Wiley \& Sons Ltd. This work is made available online in accordance with the publisher's policies. Please refer to any applicable terms of use of the publisher.

\section{General rights}

Copyright for the publications made accessible via the Queen's University Belfast Research Portal is retained by the author(s) and / or other copyright owners and it is a condition of accessing these publications that users recognise and abide by the legal requirements associated with these rights.

Take down policy

The Research Portal is Queen's institutional repository that provides access to Queen's research output. Every effort has been made to ensure that content in the Research Portal does not infringe any person's rights, or applicable UK laws. If you discover content in the Research Portal that you believe breaches copyright or violates any law, please contact openaccess@qub.ac.uk. 


\section{Treatment for erectile dysfunction among older men in}

\section{Northern Ireland}

David W Donnelly, ${ }^{1}$ Therese Kearney, ${ }^{1}$ Eilis McCaughan, ${ }^{2}$ Amy Downing,${ }^{3,4}$ David Weller, ${ }^{5}$ Adam W Glaser, ${ }^{3,4^{*}}$ Anna Gavin ${ }^{1 *}$

*Anna Gavin and Adam Glaser are co-senior authors.

Correspondence to David Donnelly at david.donnelly@qub.ac.uk.

1. Northern Ireland Cancer Registry. Centre for Public Health, Queen's University Belfast. Mulhouse Building, Grosvenor Road, BT12 6DP

2. Institute of Nursing and Health Research, Ulster University, Coleraine, BT52 1SA

3. Leeds Institute of Cancer and Pathology, University of Leeds, Leeds, LS2 9JT

4. Leeds Institute of Data Analytics, University of Leeds, Leeds, LS2 9JT

5. Usher Institute of Population Health Sciences and Informatics, University of Edinburgh, Edinburgh, EH8 9DX

Keywords: erectile dysfunction, sexual health, older men, medication, treatment 


\section{ABSTRACT}

\section{Background}

Erectile dysfunction is common among older men; however, diagnosis and treatment compared to reported prevalence is low. We aim to identify the degree to which older men are offered treatment for the condition and determine the level of unmet need within Northern Ireland (NI).

\section{Methodology}

Analysis of data collected using a cross-sectional survey was conducted for men aged $\geq 60$ years with data weighted to the $\mathrm{NI}$ population by age and deprivation. Respondents answered questions on sociodemographic factors, health-related characteristics, ability to function sexually, level of sexual interest and activity, and any treatment offered to improve erections in the last 3 years. Results are presented as proportions reporting treatment receipt, with differences by respondent characteristics assessed using chi-square tests and multivariable logistic regression.

\section{Results}

Among 2,597 respondents, $46.5 \%$ reported erectile dysfunction. One quarter $(25.8 \%)$ recalled being offered either medication, devices or specialised services to improve erections. The offer of treatment was associated with younger age, being separated or divorced, higher number of long-term conditions, and greater interest in sex. Of men reporting erectile dysfunction and offered medication, $28.8 \%$ found them helpful and currently use them. 


\section{Conclusions}

As a result of not being offered treatment or not finding treatment useful, $93 \%$ of men reporting erectile dysfunction have no help with the condition. This is a likely consequence of treatment availability through the NHS in $\mathrm{NI}$, but also suggests that healthcare professionals need to engage more proactively with older men, discussing sexual health routinely and following up those treated for the condition. 


\section{What's known}

Erectile dysfunction (ED) is common among older men and is associated with poor general health and well-being. However, despite treatments for ED being available, diagnosis and treatment of the condition is low compared to its reported prevalence.

\section{What's new}

Almost half of men aged 60 and over report moderate-to-severe ED, yet $93 \%$ of men reporting ED have no help with it as a result of not being offered treatment or not finding treatment helpful. Consequently, there is a need to address the lack of offered assistance for the condition and to provide additional follow up to those not finding treatment helpful. 


\section{INTRODUCTION}

Erectile dysfunction (ED) is common among older men and increases with advancing age..$^{1-3}$ In addition to the significant emotional and relationship difficulties ${ }^{4,5}$ that these problems cause, ED is a recognised indicator of cardiovascular disease, ${ }^{6}$ and is associated with hypertension, diabetes and depression. ${ }^{7}$ Those with poorer general health are also more likely to report lower levels of sexual activity and higher levels of sexual problems..$^{8,9}$

Despite these issues, diagnosis and treatment of ED compared to its reported prevalence by men in epidemiological studies is low. ${ }^{10-12}$ While this is partly because of men not seeking help for a variety of reasons, such as embarrassment or believing the condition was not severe or a normal part of ageing, ${ }^{13}$ there is also evidence indicating that even when men discuss ED with a health professional many do not receive treatment or use medication. ${ }^{12}$ With treatment rates consequently low, one solution is for health professionals to initiate discussion on sexual health with patients when they attend medical facilities for other reasons. ${ }^{12}$ However, this is not common practice with less than $4 \%$ of men indicating that they have been asked by a doctor about possible sexual difficulties in a routine visit. ${ }^{13}$ Despite this evidence, no detailed UK studies have investigated the degree to which older men in the general population, regardless of whether they have reported ED, are being offered help with their sexual health.

In this study we investigate the frequency of offers of medication, devices and specialist services via the NHS to improve erections among men aged over 60 in Northern Ireland (NI), a devolved nation of the UK. We consider all men within the 
general population (excluding those with prostate cancer) and investigate a range of sociodemographic and health-related characteristics, in addition to self-reported sexual activity levels and level of interest in sex. Consequently, we aim to identify whether treatment is being offered to men in need of help and determine the level of unmet need within NI. 


\section{METHODOLOGY}

\section{1: Data collection}

The data utilised were originally collected as part of the Life After Prostate Cancer Diagnosis $^{14}$ (LAPCD) project for the purpose of acting as a general population baseline. In this survey, 10,000 men from $\mathrm{NI}$, with no history of prostate cancer and aged over 40, were randomly selected from the NI General Practice Register by the Business Service Organisation (BSO). The sample was stratified by age based upon the age distribution of prostate cancer survivors (alive 1-3 years after diagnosis), while the NI Cancer Registry checked that men with a previous prostate cancer diagnosis were excluded.

Rigorous procedures, documented in detail by Downing et al ${ }^{14}$ were put in place to ensure respondent confidentiality. In brief, BSO dispatched questionnaires by post in September and October 2016, with a unique reference number (URN) on the form. Responses were returned to an external survey provider (Picker Institute Europe) who entered the data associated with the URN. Geographic information such as Health Trust, deprivation quintile derived from the Super Output Area level NI multiple deprivation measure ${ }^{15}$ and urban/rural indicator assigned using the $\mathrm{NI}$ statistical classification and delineation of settlements, ${ }^{16}$ was provided by BSO and linked via URN. An anonymised database was then prepared and made available for analysis.

\section{2: Questions}

The survey was adapted from the $\angle A P C D$ survey of prostate cancer survivors and was tested for acceptability, content and clarity by a focus group of older men, contacted 
through a local charity. Questions included information on marital status, long-term conditions (e.g. heart condition, diabetes) and height and weight which were then used to determine body mass index (BMI). General health was evaluated using the EQ-5D self-assessed health score which ranges from 0 (worst health you can imagine) to 100 (best health you can imagine). ${ }^{17}$

Responses to questions from the 26-item Expanded Prostate Cancer Composite $\left(\right.$ EPIC-26) ${ }^{18}$ were used to determine whether men experienced ED or overall sexual dysfunction, with "Very poor to none" and "Poor" ability to have an erection in the past four weeks constituting ED (q9a, supplementary file 1) and "No problem" with sexual function in the past four weeks (q13, supplementary file 1) constituting no problem with sexual function. Two additional sexual questions from the EORTC QLQ-PR25 ${ }^{19}$ were included to determine the extent of interest in sex and the extent of sexual activity (q15-16, supplementary file 1). Three questions were included specifically on whether men had used one or more of three services to improve erections in the past 3 years: medications (e.g. tablets, penis injections, gels), devices (e.g. vacuum pump, penile prosthesis), and specialised services (e.g. counselling, psychosexual clinics). The respondent had seven response options: "I was not offered this", "I was offered this but did not want it", "I was offered this but have not tried it", "I was offered this and tried it but it was not helpful", "I was offered this and it helped, but I am not using it now", "I was offered this, it helps and I use it sometimes" and "I was offered this, it helps and I use it often" (q17-19, supplementary file 1).

\section{3: Statistical analysis}

The sample was designed to match the age structure of prostate cancer survivors, thus only $12.1 \%$ of the sample was aged $40-59$. This is considerably lower than the $\mathrm{NI}$ 
general population, where $59.6 \%$ of men aged 40 and over are aged $40-59 .{ }^{20}$ In order to increase the representativeness of the results men aged $40-59$ were thus excluded and data were weighted by age and deprivation to that of the $2011 \mathrm{NI}$ Census of Population. ${ }^{20}$

Missing values to individual questions were excluded from the analysis, with responses to individual questions thus reported as proportions of the men who responded to that question. Chi-square tests were used to compare proportions, with the Bonferroni correction applied to compensate for multiple comparisons.

Multivariable binary logistic regression was used to model whether or not offers for services had been made for all men, those currently reporting ED and those currently reporting no problems with sexual function. Respondents' age, Health Trust of residence, area based deprivation, urban/rural status, marital status, number of longterm conditions, general health, body mass index (BMI), extent of interest in sex, extent of sexual activity, and reporting ED (for all men only) were investigated as independent variables. A backwards stepwise approach was used with results presented as adjusted odds ratios with 95\% confidence intervals.

Analysis was conducted using SPSS v22 (IBM Corp, 2013, NY USA). 


\section{RESULTS}

A total of 2,597 men aged 60 and over responded to the survey, a response rate of $30.9 \%$ in that age group. Key characteristics of survey participants are shown in Table 1. The mean age of respondents was 70.4 years, with $53.3 \%$ of men aged $60-69$ and $75.2 \%$ married. Of respondents $22.0 \%$ of men were resident in the least deprived areas compared to $17.8 \%$ in the most deprived areas, while $64.3 \%$ of respondents were resident in urban areas. The mean self-assessed health score was 77.2 with $22.2 \%$ of men scoring under 70 , while $20.8 \%$ of men reported three or more long-term conditions and $20.5 \%$ were classified as obese according to their BMI.

Among men aged 60 and over $46.5 \%$ reported ED, with this proportion increasing by age (34.6\% for $60-69$ year olds vs. $81.0 \%$ for $80+$ year olds, $p<0.001)$. Prevalence of ED was also greater among widowed men, those with a higher number of long-term conditions, men classified as obese and those with poorer general health (all $p<0.001$ ). Conversely $42.1 \%$ of men aged 60 and over reported no problems with sexual function (Table 1).

\subsection{Offer of treatment to improve erections}

Among all men aged 60 and over in the general population $18.0 \%$ recalled (either opportunistically or in response to a request) being offered medications to improve erections in the past 3 years, $2.9 \%$ being offered devices or aids, and $3.1 \%$ being offered specialised services. One in five (19.1\%) men was offered at least one of these services. Specifically among men reporting ED, $24.8 \%$ reported being offered medications, $4.4 \%$ were offered devices or aids and $3.6 \%$ were offered specialised services, with $25.8 \%$ being offered at least one of these. Of those men currently 
reporting no problems with sexual function, $7.7 \%$ recalled being offered one of these services in the past 3 years (Table 2).

For all respondents, medications to improve sexual function were more commonly offered to those aged 60-69 and 70-79 compared to those aged 80 and over $(p<0.001)$; however there was no significant relationship to age for the offer of devices or specialised services to improve sexual function. Single men were less likely to be offered services, with help more commonly offered to those separated/divorced $(p<0.001)$. Men with greater numbers of long-term conditions were more likely to report an offer of all three services (medications: $p<0.001$, devices: $p=0.005$, specialised services: $p=0.008)$. Poorer general health $(p<0.001)$ and higher deprivation $(p=0.003)$ were significantly associated with the offer of devices, while higher BMI was significantly associated with the offer of medication $(p<0.001)$. Neither Health Trust nor urban/rural indicator of area of residence were related to the offer of services (Table 2).

Among the subgroup currently reporting $\operatorname{ED}(n=1,128)$, the offer of services decreased with increasing age $(p<0.001)$, with those who are single and widowed less likely than divorced/separated men to be offered medications $(p<0.001)$. This pattern was also evident for men reporting no problems with sexual function $(p=0.004)$. There were no other significant associations with socio-demographic factors for men either reporting ED or no problems with sexual function (table 2).

Among all men aged 60 and over in the general population and those specifically reporting ED, medications were more commonly offered to those very interested in sex $(p=0.002$ and $p<0.001$ respectively), while devices $(p=0.002)$ and specialised services $(p<0.001)$ were more commonly offered to men in the general population who 
indicated that they were not interested in sex. However, among those currently reporting ED interest in sex was not a significant factor in the offer of devices or specialised services. Greater reported levels of sexual activity were associated with the offer of services among those reporting ED $(p<0.001)$; however, extent of sexual activity had no significant relationship to the offer of services to improve sexual function overall or for men reporting no problems with sexual function (Table 3).

In multivariable analysis the strongest predictor of the offer of services in order to improve erections over the past 3 years to all responders aged 60 and over was reporting of ED in the survey. Men who were aged 80 and over $(p<0.001)$ or were single (compared to married) $(p=0.011)$ were less likely to be offered services, while those separated/divorced (compared to married) $(p=0.009)$, with one or more longterm conditions $(p=0.002)$, classified as overweight $(p=0.037)$ and reporting greater interest in sex $(p<0.001)$ were more likely to be offered help. Similar patterns were

evident for men currently reporting ED, with the exception that BMI was not a significant predictor of the offer of services. Similarly age, marital status, number of long-term conditions and BMI, but not extent of interest in sex, were associated with the offer of services for men currently reporting no problems with sexual function (Table 4).

\subsection{Effectiveness of treatment to improve erections}

The proportion of all men who reported being offered treatments for ED and are currently using them because they were helpful was $36.4 \%$ for medication, $8.7 \%$ for devices, and $12.5 \%$ for specialised services. A further $15.8 \%$ of men found medications useful but were not currently using them, with similar proportions finding devices (11.6\%) and specialised services helpful (15.3\%) without current use. High 
proportions of men offered devices $(59.4 \%)$ or specialised services $(61.1 \%)$ did not want or have not tried them (Figure 1).

Among the group of men currently reporting ED and offered medications in the past 3 years $28.8 \%$ reported that they were helpful and currently used $(7.1 \%$ of all men reporting ED regardless of whether they had been offered help); however, $31.8 \%$ indicated that they had tried them but not found them useful. Among men currently reporting no problems with sexual function who had been offered medications in the past 3 years $46.0 \%$ reported that they were helpful and currently used, while only $3.2 \%$ indicated that they had tried them but not found them useful (Figure 2). 


\section{DISCUSSION}

This large population based survey has examined offers of treatment for ED among older men for the first time in NI. We found in keeping with studies in UK ${ }^{2}$ and USA ${ }^{9}$ that almost half of men aged 60 and over report moderate-to-severe ED. Despite the high prevalence of ED, and the relationship between ED and other diseases, ${ }^{4-9}$ only one in five of these men reported being offered treatment to improve erections over the past 3 years. This proportion decreases with increasing age, but increases with extent of interest in sex reported and number of long-term conditions, the latter suggesting greater level of discussion with service providers regarding sexual issues when there is regular service contact.

This finding is supported by previous studies that have focused on treatment rates of ED compared to its reported prevalence. Observational studies in the USA indicate that significantly fewer men receive ED diagnosis and treatment than the proportion of men who experience it. ${ }^{10}$ Despite being a common condition, the proportion of men who seek help for ED from a doctor ranges from $22-26 \%,{ }^{13,21}$ or $35 \%$ from a health professional in general. ${ }^{11}$ This proportion increases with severity, yet still less than half of men with severe ED seek professional help for the condition. ${ }^{11}$

A range of reasons contribute to men not receiving, or being offered treatment for ED. One of the primary contributors in $\mathrm{NI}$ is restrictions on the availability of prescription medication for this condition via the NHS. Unlike in England, Wales and Scotland, sildenafil, tadalafil and vardenafil cannot be prescribed by a primary care (general) practitioner (GP) unless the patients had other medical conditions or treatment such as diabetes or prostatectomy, ${ }^{22}$ instead only a specialist can prescribe these drugs 
putting greater onus on the men suffering from this condition to seek assistance. While the availability of Viagra via a pharmacist without prescription has recently become an option in $\mathrm{NI}$ and may allow additional men to get help, this is without the benefit of professional medical advice or discussion about potential causes of the problem.

However older men often find asking for help with their sex life challenging because of issues including embarrassment and shame..$^{23,24}$ They can believe that problems with sexual function are normal given their age and be unaware of its relationship with other health conditions. ${ }^{13,21}$ There are also barriers on the health service side. Only $4 \%$ of men report being asked by a doctor about sexual problems during a routine visit, despite over one third of men believing that they should. ${ }^{13}$ GPs report time pressures, lack of training, concerns over use of appropriate language, gender and ethnic background differences as reasons for lack of engagement with patients on

these issues. ${ }^{25,26}$ However, other reasons such as ageism and being uncomfortable talking about sex are also known barriers for healthcare professionals. ${ }^{27,28}$

\section{1: Service implications}

Overcoming these barriers is not a simple task, but is potentially worthwhile as ED is not only a health condition in of itself but can also be a symptom of cardiac disease ${ }^{6}$ as well as having an association with diabetes, ${ }^{7}$ and depression ${ }^{4}$ while men experiencing poorer general health are less likely to be sexually active and more likely to report sexual problems. ${ }^{8,9} \mathrm{New}$ ways of breaking down the barriers surrounding discussions of this condition, such as online information, ${ }^{29}$ can help in increasing clinical diagnosis of ED. There are also educational and awareness-raising priorities for healthcare professionals (including GPs, who are, in NI, most likely to be the primary source of advice about sexual difficulties); while patients over 60 typically have 
several morbidities, ${ }^{30}$ it is important to consider sexual function amongst the other reasons these patients may consult a doctor.

It is essential to identify solutions which are effective and yet do not put extra burden on already stretched primary care services. ${ }^{31}$ Approaches might include routine use of a simple sexual health instrument that facilitates the provision of some basic support and signposting onwards to appropriate resources. Recognising the growing need for sexual care within an ageing population, and mindful of limited resources and the sensitivity of the subject area, it may be necessary to develop online self-management programmes where men/couples would be empowered to manage their own sexual issues with appropriate support from health professionals where necessary.

Common co-morbidities such as depression and diabetes are strongly associated with sexual health problems in elderly people. ${ }^{32,33}$ Incorporation of sexual health screening into existing management protocols for these common conditions should thus be encouraged. Such screening for common problems in primary care elderly populations is entirely feasible ${ }^{34}$ - issues relating to sexuality could readily be incorporated into the growing number of geriatric screening instruments already available.

Healthcare professionals need training to provide them with the knowledge and skills to engage with patients regarding sexual health. ${ }^{35}$ Such training should challenge attitudes to sex among healthcare professionals and illustrate how these influence their clinical behavior, as well as highlighting the importance of taking the lead in discussions with men on sexual issues. GPs should approach the topic with patients routinely, normalising the issue, treating it like any other healthcare challenge. This will give the patient the message that sexual health is an important issue and needs to be addressed. Through time, the stigma will be reduced. 
If an increase in diagnosis resulted from any additional initiatives, this would likely lead to increased referrals for sexual difficulties, and additional services may need to be made available to address any unmet need. Five Health Trusts currently exist in $\mathrm{NI}$, yet in a survey in which four of these Trusts responded, only two offered an ED clinic, two counselling and one a psychosexual clinic. ${ }^{36}$ This is slightly lower than in other parts of the UK; however, not all Clinical Commissioning Groups (CCGs)/Health Boards in England, Wales and Scotland offer specialised treatment for erectile and other forms of sexual dysfunction, ${ }^{36}$ although GPs in each CCG/Health Board will be able to provide help in many circumstances.

\section{2: Treatment effectiveness}

Worryingly many men in receipt of treatments to improve erections do not find these treatments helpful or are unwilling to use them. This reflects findings regarding the use of penile rehabilitation programmes following prostate cancer where evidence shows that most men stop using ED treatments within 2 years. ${ }^{37,38}$ More research in this area is warranted to determine why many men do not find these services helpful or are unwilling to use them. With ongoing advances in pharmacological treatment options, it is unfortunate that around $93 \%$ of men who report ED are either not offered services to improve sexual function or are offered them but do not use them. Of those men who do not report sexual functioning problems, almost half of those receiving treatment found them helpful suggesting that there are definite benefits to be had.

\subsection{Study limitations}

This study uses data originally collected to compare prevalence of sexual dysfunction (and other conditions) in the general population with that of prostate cancer survivors. Consequently, men with prostate cancer were excluded at the data collection phase, 
which may result in an underestimation in the prevalence of ED in the general population. In addition, ED and sexual dysfunction in general are identified through self-assessment and may not represent clinically recognised definitions of the conditions.

The survey response rate of $30 \%$ is less than optimal and may result in responder bias. However, the response rate is better than many other health surveys featuring personal sexual function questions, ${ }^{12,13,21}$ while compared to health surveys without sexual questions which feature face-to-face interviews and higher response rates, ${ }^{39,40}$ the results for health-related quality of life (measured using the EQ-5D-5L) and BMI are broadly comparable. In addition the questions on being offered treatment over the last 3 years may be subject to recall bias as respondents may not remember whether or not such offers had been made, particularly if they were not experiencing sexual function difficulties.

Finally, this study is cross sectional in nature, thus causal relationships between men reporting treatment offers and any sexual problems experienced cannot be inferred. For example, men currently reporting ED may have had the condition for some time and thus be more likely to be offered treatment to improve sexual function over the last 3 years, but conversely men reporting good ability to function sexually may do so as a result of using services after being offered them.

\subsection{Conclusions}

Almost half of men aged 60 and over report moderate-to-severe ED, but only one quarter of these men were offered services to improve their condition, while only $7 \%$ of men who report ED take medication because they find it helpful. A major contributor to high level of unmet need is likely to be the restrictions placed upon GPs in NI with 
regards the type of men that they can prescribe help for. While this particular situation does not exist in other parts of the UK, other more general barriers to receipt of treatment include men themselves not seeking assistance. With ED a precursor or warning sign for cardiac disease and sexual health being associated with general wellbeing, more needs to be done to encourage men to seek help for the condition. Health professionals should thus be routinely discussing sexual issues with older men that they treat for other conditions in an effort to address the unmet need for help with this condition, as the onus, particularly in $\mathrm{NI}$, is currently on men to seek help for themselves. 


\section{Acknowledgements}

The authors thank all the men who responded to the survey. We acknowledge the following people for their contribution to the development, setting up and running of the study: Heather Kinnear, Oonagh McSorley, Victoria Cairnduff, Conan Donnelly, Linda Roberts, Adrian Slater, the LAPCD User Advisory Group and Clinical and Scientific Advisory Group, Picker Institute Europe and Business Services Organisation (NI). The authors thank Age Concern in NI for providing feedback on the survey content and layout.

\section{Disclosures}

All authors declare no support from any organisation for the submitted work; no financial relationships with any organisations that might have an interest in the submitted work in the previous three years and no other relationships or activities that could appear to have influenced the submitted work.

\section{Author contributions}

A Glaser and A Gavin are the principal investigators with the remaining authors' coinvestigators. D Donnelly conducted the statistical analysis. A Glaser, A Gavin, A Downing and T Kearney contributed to the design and management of the study. All authors contributed to interpreting the results and drafting the manuscript.

\section{Funding}

The Life After Prostate Cancer Diagnosis study was funded by the Movember Foundation, in partnership with Prostate Cancer UK, as part of the Prostate Cancer Outcomes programme, grant number BO26/MO. 


\section{Research ethics}

Ethical approval was granted by The Office of Research Ethics Committees NI (ORECNI). Queen's University Belfast were study sponsors. 


\section{REFERENCES}

1. Rosen R, Altwein $\mathrm{J}$, Boyle $\mathrm{P}$, et al. Lower urinary tract symptoms and male sexual dysfunction: the multinational survey of the ageing male (MSAM-7). Eur Urol 2003; 44: 637-49.

2. Lee DM, Nazroo J, O'Connor DB, Blake M, Pendleton N. Sexual health and well-being among older men and women in England: Findings from the English Longitudinal Study of ageing. Arch Sex Behav 2016; 45:133-44. doi: 10.1007/s10508-014-0465-1.

3. Donnelly DW, Donnelly C, Kearney $\mathrm{T}$, et al. Urinary, bowel and sexual health in older men from Northern Ireland. BJU Int. In press

4. Huri HZ, Mat Sanusi ND, Razack AH, Mark R. Association of psychological factors, patients' knowledge, and management among patients with erectile dysfunction. Patient Prefer Adherence 2016; 10:807-23. doi:10.2147/PPA.S99544.

5. Rosen RC, Heiman JR, Long JS, et al. Men with Sexual Problems and Their Partners: Findings from the International Survey of Relationships. Arch Sex Behav 2016; 45:159-73. doi:10.1007/s10508-015-0568-3.

6. Gandaglia G, Briganti A, Jackson G, et al. A systematic review of the association between erectile dysfunction and cardiovascular disease. Eur Urol 2014; 65:968-78. doi:10.1016/j.eururo.2013.08.023.

7. Kouidrat $\mathrm{Y}$, Pizzol D, Cosco T, et al. High prevalence of erectile dysfunction in diabetes: a systematic review and meta-analysis of 145 studies. Diabet Med 2017; 34:1185-92. doi:10.1111/dme.13403.

8. Field $\mathrm{N}$, Mercer $\mathrm{CH}$, Sonnenberg $\mathrm{P}$, et al. Associations between health and sexual lifestyles in Britain: findings from the third National Survey of Sexual Attitudes and Lifestyles (Natsal-3). Lancet 2013; 382:1830-44. doi:10.1016/s0140-6736(13)62222-9.

9. Lindau ST, Schumm P, Laumann EO, et al. A study of sexuality and health among older adults in the United States. N Engl J Med 2007; 357:762-74. doi: 10.1056/NEJMoa067423.

10. Mulhall JP, Luo X, Zou KH, et al. Relationship between age and erectile dysfunction diagnosis or treatment using real-world observational data in the USA. Int J Clin Pract 2016; 70:1012-18. doi:10.1111/ijcp.12908

11. Williams $\mathrm{P}$, Bandhoo $\mathrm{S}, \mathrm{McBain} \mathrm{H}$, et al. Erectile dysfunction and its detection in the healthcare setting: 10 years on. Int J Clin Pract 2015; 69:910-1. doi:10.1111/ijcp.12659

12. Jannini EA, Sternbach N, Limoncin E, et al. Health-related characteristics and unmet needs of men with erectile dysfunction: A survey in five European countries. J Sex Med 2014; 11:40-50. doi:10.1111/jsm.12344.

13. Moreira ED, Glasser DB, Nicolosi A, et al. Sexual problems and help-seeking behaviour in adults in the United Kingdom and continental Europe. Sex Med 2008; 101:1005-11. doi:10.1111/j.1464410X.2008.07453.x

14. Downing $A$, Wright $P$, Wagland $R$, et al. Life after prostate cancer diagnosis: protocol for a UKwide patient-reported outcomes study. BMJ open 2016; 6:e013555. doi:10.1136/bmjopen-2016013555.

15. NI Statistics and Research Agency. NI Multiple Deprivation Measure. https://www.nisra.gov.uk/statistics/deprivation/northern-ireland-multiple-deprivation-measure2010-nimdm2010. Accessed July 2017.

16. NI Statistics and Research Agency. Urban-Rural Classification. https://www.nisra.gov.uk/support/geography/urban-rural-classification. Accessed July 2017.

17. Herdman M, Gudex C, Lloyd A, et al. Development and preliminary testing of the new five-level version of EQ-5D (EQ-5D-5L).Qual Life Res 2011; 20:1727-36. doi:10.1007/s11136-011-9903-x.

18. Szymanski KM, Wei JT, Dunn RL, Sanda MG. Development and validation of an abbreviated version of the expanded prostate cancer index composite instrument for measuring health-related quality of life among prostate cancer survivors.Urology 2010; 76:1245-50. doi:10.1016/j.urology.2010.01.027.

19. van Andel G, Bottomley A, Fossa SD, et al. An international field study of the EORTC QLQ-PR25: a questionnaire for assessing the health-related quality of life of patients with prostate cancer. Eur J Cancer 2008; 44:2418-24.

20. NI Statistics and Research Agency. 2011 Census. https://www.nisra.gov.uk/statistics/census. Accessed July 2017. 
21. Laumann EO, Glasser DB, Neves RCS, Moreira ED. A population-based survey of sexual activity, sexual problems and associated help-seeking behaviour patterns in mature adults in the United States of America. Int J Imp Res 2009; 21:171-8. doi:10.1038/ijir.2009.7.

22. HSC Business Services Organisation. Drug Tariff Part XI (b) Drugs to be prescribed in certain circumstances. http://www.hscbusiness.hscni.net/services/2034.htm. Accessed April 2018.

23. Farrell J, Belza B. Are older patients comfortable discussing sexual health with nurses? Nurs Res 2012; 61:51-7. doi: 10.1097/NNR.0b013e31823a8600.

24. Bauer M, Haesler E, Fetherstonhaugh D. Let's talk about sex: older people's views on the recognition of sexuality and sexual health in the health-care setting. Health Expect 2016; 19:123750. doi:10.1111/hex.12418.

25. Gott M, Galena E, Hinchliff S, Elford H. "Opening a can of worms": GP and practice nurse barriers to talking about sexual health in primary care. Fam Pract 2004; $21: 528-536$. doi:10.1093/fampra/cmh509.

26. Byrne M, Doherty S, McGee HM, Murphy AW. General practitioner views about discussing sexual issues with patients with coronary heart disease: a national survey in Ireland. BMC Fam Pract 2010; 11:40. doi:10.1186/1471-2296-11-40.

27. Ussher JM, Perz J, Gilbert E, et al. Talking about sex after cancer: a discourse analytic study of health care professional accounts of sexual communication with patients. Psychol Health 2013; 28:1370-90. doi:10.1080/08870446.2013.811242.

28. Haesler E, Bauer M, Fetherstonhaugh D. Sexuality, sexual health and older people: A systematic review of research on the knowledge and attitudes of health professionals. Nurse Educ Today 2016; 40:57-71. doi:10.1016/j.nedt.2016.02.012.

29. NHS Choices. Erectile dysfunction (impotence). https://www.nhs.uk/conditions/erection-problemserectile-dysfunction. Accessed Apr 2018.

30. Yarnall AJ, Sayer AA, Clegg A, Rockwood K, Parker S, Hindle JV. New horizons in multimorbidity in older adults. Age Ageing 2017; 46:882-8. doi:10.1093/ageing/afx150.

31. Baird B, Charles A, Honeyman M, Maguire D, Das P. Understanding pressures in general practice. https://www.kingsfund.org.uk. Accessed July 2018.

32. Field N, Prah P, Mercer $\mathrm{CH}$, et al. Are depression and poor sexual health neglected comorbidities? Evidence from a population sample. BMJ Open 2016; 6:e010521. doi:10.1136/bmjopen-2015-010521.

33. Bjerggaard M, Charles M, Kristensen E, Lauritzen T, Sandbæk A, Giraldi A. Prevalence of Sexual Concerns and Sexual Dysfunction among Sexually Active and Inactive Men and Women with Screen-Detected Type 2 Diabetes. Sex Med 2015; 3:302-10. doi:10.1002/sm2.91.

34. Piccoliori G, Gerolimon E, Abholz HH. Geriatric assessment in general practice using a screening instrument: is it worth the effort? Results of a South Tyrol Study. Age Ageing 2008; 14:647-52. doi:10.1093/ageing/afn161.

35. Jonsdottir JI, Zoega S, Saevarsdottir T, et al. Changes in attitudes, practices and barriers among oncology health care professionals regarding sexual health care: Outcomes from a 2-year educational intervention at a University Hospital. Eur J Oncol Nurs 2016; 21:24-30. doi:10.1016/j.ejon.2015.12.004

36. Prostate Cancer UK. Five services all men should expect to receive. http:/bettercare.prostatecanceruk.org. Accessed Sept 2017.

37. Nelson CJ, Lacey S, Kenowitz J, et al. Men's experience with penile rehabilitation following radical prostatectomy: a qualitative study with the goal of informing a therapeutic intervention. Psychooncology 2015; 24:1646-54. doi:10.1002/pon.3771.

38. Polito M1, d'Anzeo G, Conti A, Muzzonigro G. Erectile rehabilitation with intracavernous alprostadil after radical prostatectomy: refusal and dropout rates. BJU Int 2012; 110:e954-7. doi:10.1111/j.1464-410X.2012.11484.x.

39. Department of Health. Health Survey Northern Ireland: First results 2015/16 https://www.healthni.gov.uk/sites/default/files/publications/health/hsni-first-results-15-16.pdf. Accessed Dec 2017.

40. Department of Health. Health Survey Northern Ireland: First results 2012/13 https://www. healthni.gov.uk/sites/default/files/publications/health/hsni-first-results-15-16.pdf. Accessed Dec 2017. 
Table 1: Respondent characteristics and proportion reporting erectile dysfunction or no problems with sexual function

\begin{tabular}{|c|c|c|c|}
\hline & $\begin{array}{l}\text { Number (\%) of } \\
\text { respondents }\end{array}$ & $\begin{array}{l}\text { Proportion } \\
\text { reporting erectile } \\
\text { dysfunction }\end{array}$ & $\begin{array}{l}\text { Proportion } \\
\text { reporting no } \\
\text { problems with } \\
\text { sexual function }\end{array}$ \\
\hline All respondents & $2,597(100 \%)$ & $46.5 \%$ & $42.1 \%$ \\
\hline Age group & & $p<0.001^{s}$ & $p<0.001^{s}$ \\
\hline $60-69$ & $1,385(53.3 \%)$ & $34.6 \%$ & $45.7 \%$ \\
\hline $70-79$ & $830(32.0 \%)$ & $53.2 \%$ & $37.8 \%$ \\
\hline $80+$ & $382(14.7 \%)$ & $81.0 \%$ & $37.1 \%$ \\
\hline Health Trust & & $p=0.658$ & $p<0.001^{s}$ \\
\hline Belfast & $500(19.2 \%)$ & $46.2 \%$ & $36.8 \%$ \\
\hline Northern & $671(25.8 \%)$ & $48.9 \%$ & $42.7 \%$ \\
\hline South-Eastern & $544(20.9 \%)$ & $44.3 \%$ & $50.1 \%$ \\
\hline Southern & $442(17.0 \%)$ & $46.6 \%$ & $41.9 \%$ \\
\hline Western & $441(17.0 \%)$ & $46.0 \%$ & $37.7 \%$ \\
\hline Deprivation indicator & & $p=0.010$ & $p<0.001^{s}$ \\
\hline Least deprived & $571(22.0 \%)$ & $42.1 \%$ & $48.8 \%$ \\
\hline Quintile 2 & $519(20.0 \%)$ & $43.8 \%$ & $43.3 \%$ \\
\hline Quintile 3 & $527(20.3 \%)$ & $45.5 \%$ & $43.2 \%$ \\
\hline Quintile 4 & $519(20.0 \%)$ & $50.9 \%$ & $39.1 \%$ \\
\hline Most deprived & $461(17.8 \%)$ & $51.2 \%$ & $34.4 \%$ \\
\hline Urban/rural indicator & & $p=0.377$ & $p=0.208$ \\
\hline Urban & $1,669(64.3 \%)$ & $47.2 \%$ & $41.2 \%$ \\
\hline Rural & $928(35.7 \%)$ & $45.3 \%$ & $43.8 \%$ \\
\hline Marital status* & & $p<0.001^{S}$ & $p=0.024$ \\
\hline Married & $1,860(75.2 \%)$ & $45.2 \%$ & $41.5 \%$ \\
\hline Separated/Divorced & $218(8.8 \%)$ & $44.4 \%$ & $36.9 \%$ \\
\hline Widowed & $225(9.1 \%)$ & $60.6 \%$ & $46.5 \%$ \\
\hline Single & $171(6.9 \%)$ & $42.0 \%$ & $51.5 \%$ \\
\hline Number of long-term conditions & & $p<0.001^{s}$ & $p<0.001^{s}$ \\
\hline No conditions & $747(28.7 \%)$ & $29.8 \%$ & $55.2 \%$ \\
\hline 1-2 conditions & $1,311(50.5 \%)$ & $46.0 \%$ & $41.2 \%$ \\
\hline
\end{tabular}




\begin{tabular}{|l|c|c|c|}
\hline 3 or more conditions & $540(20.8 \%)$ & $71.4 \%$ & $25.9 \%$ \\
\hline Body Mass Index (BMI) & & & \\
\hline Under \& healthy weight (0-25) & & $\mathrm{p}<0.001^{\mathrm{S}}$ & $\mathrm{p}<0.001^{\mathrm{S}}$ \\
\hline Overweight (25-30) & $717(30.3 \%)$ & $42.0 \%$ & $46.6 \%$ \\
\hline Obese (30+) & $1,164(49.2 \%)$ & $44.0 \%$ & $43.0 \%$ \\
\hline & $486(20.5 \%)$ & $56.7 \%$ & $32.8 \%$ \\
\hline Self-assessed health score & & & \\
\hline 90 and over (better health) & & $\mathrm{p}<0.001^{\mathrm{S}}$ & $\mathrm{p}<0.001^{\mathrm{S}}$ \\
\hline $80-89.9$ & $974(38.4 \%)$ & $30.6 \%$ & $55.1 \%$ \\
\hline $70-79.9$ & $598(23.5 \%)$ & $43.7 \%$ & $43.0 \%$ \\
\hline Under 70 (poorer health) & $404(15.9 \%)$ & $56.0 \%$ & $36.4 \%$ \\
\hline
\end{tabular}

Notes:

Data are weighted to the NI population by age and deprivation.

Breakdown by self-reported erectile/sexual dysfunction excludes respondents who did not answer that question.

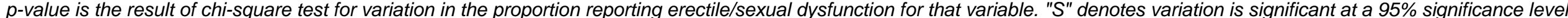
after Bonferonni correction for multiple comparisons

* Includes civil partnership equivalents. 
Table 2: Proportion of men aged 60 and over offered treatment to aid or improve erections by demographic and

\section{health-related characteristics}

\begin{tabular}{|c|c|c|c|c|c|c|c|c|c|c|c|c|}
\hline & \multicolumn{4}{|c|}{$\begin{array}{l}\text { Proportion of men aged } 60 \text { and over who had been } \\
\text { offered service to improve erections }\end{array}$} & \multicolumn{4}{|c|}{$\begin{array}{l}\text { Proportion of men aged } 60 \text { and over currently } \\
\text { reporting erectile dysfunction who had been offered } \\
\text { service to improve erections }\end{array}$} & \multicolumn{4}{|c|}{$\begin{array}{l}\text { Proportion of men aged } 60 \text { and over currently } \\
\text { reporting no problems with sexual function who had } \\
\text { been offered service to improve erections }\end{array}$} \\
\hline & $\begin{array}{c}\text { Medications } \\
(\mathrm{n}=2,331)\end{array}$ & $\begin{array}{l}\text { Devices or } \\
\quad \text { aids } \\
(\mathrm{n}=2,312)\end{array}$ & $\begin{array}{l}\text { Specialised } \\
\text { services } \\
(n=2,307)\end{array}$ & $\begin{array}{c}\text { Any service } \\
(\mathrm{n}=2,324)\end{array}$ & $\begin{array}{c}\text { Medications } \\
(\mathrm{n}=1,059)\end{array}$ & $\begin{array}{l}\text { Devices or } \\
\quad \text { aids } \\
(\mathrm{n}=1,053)\end{array}$ & $\begin{array}{l}\text { Specialised } \\
\text { services } \\
(n=1,044)\end{array}$ & $\begin{array}{l}\text { Any service } \\
(n=1,054)\end{array}$ & $\begin{array}{c}\text { Medications } \\
(\mathrm{n}=921)\end{array}$ & $\begin{array}{l}\text { Devices or } \\
\quad \text { aids } \\
(n=918)\end{array}$ & $\begin{array}{l}\text { Specialised } \\
\text { services } \\
(\mathrm{n}=917)\end{array}$ & $\begin{array}{c}\text { Any service } \\
(\mathrm{n}=918)\end{array}$ \\
\hline All respondents & $18.0 \%$ & $2.9 \%$ & $3.1 \%$ & $19.1 \%$ & $24.8 \%$ & $4.4 \%$ & $3.6 \%$ & $25.8 \%$ & $6.9 \%$ & $1.1 \%$ & $1.5 \%$ & $7.7 \%$ \\
\hline Age group & $p<0.001^{s}$ & $p=0.084$ & $p=0.173$ & $p<0.001^{s}$ & $p<0.001^{s}$ & $p=0.394$ & $p=0.446$ & $p<0.001^{s}$ & $p=0.013$ & $p=0.462$ & $p=0.118$ & $p=0.010$ \\
\hline $60-69$ & $19.1 \%$ & $2.3 \%$ & $2.5 \%$ & $19.7 \%$ & $31.2 \%$ & $3.9 \%$ & $3.8 \%$ & $31.9 \%$ & $7.3 \%$ & $1.1 \%$ & $0.9 \%$ & $7.4 \%$ \\
\hline $70-79$ & $19.9 \%$ & $3.5 \%$ & $3.7 \%$ & $21.5 \%$ & $27.0 \%$ & $5.4 \%$ & $4.2 \%$ & $28.3 \%$ & $8.7 \%$ & $1.5 \%$ & $2.8 \%$ & $10.6 \%$ \\
\hline $80+$ & $8.3 \%$ & $4.2 \%$ & $3.9 \%$ & $10.0 \%$ & $8.9 \%$ & $3.5 \%$ & $2.5 \%$ & $9.7 \%$ & $0.0 \%$ & $0.0 \%$ & $1.5 \%$ & $1.5 \%$ \\
\hline Health Trust & $p=0.746$ & $p=0.114$ & $p=0.978$ & $p=0.702$ & $p=0.928$ & $p=0.234$ & $p=0.908$ & $p=0.909$ & $p=0.390$ & $p=0.337$ & $p=0.054$ & $p=0.262$ \\
\hline Belfast & $17.7 \%$ & $3.4 \%$ & $3.3 \%$ & $18.5 \%$ & $26.2 \%$ & $5.5 \%$ & $4.4 \%$ & $26.8 \%$ & $4.2 \%$ & $0.0 \%$ & $0.0 \%$ & $4.3 \%$ \\
\hline Northern & $17.4 \%$ & $2.4 \%$ & $3.2 \%$ & $18.8 \%$ & $23.1 \%$ & $2.9 \%$ & $3.1 \%$ & $23.9 \%$ & $8.6 \%$ & $1.6 \%$ & $1.1 \%$ & $9.3 \%$ \\
\hline South Eastern & $16.6 \%$ & $2.4 \%$ & $2.9 \%$ & $17.4 \%$ & $24.8 \%$ & $4.7 \%$ & $4.5 \%$ & $25.7 \%$ & $5.2 \%$ & $0.5 \%$ & $1.5 \%$ & $6.3 \%$ \\
\hline Southern & $19.6 \%$ & $4.8 \%$ & $2.8 \%$ & $20.6 \%$ & $24.5 \%$ & $6.5 \%$ & $2.8 \%$ & $26.2 \%$ & $8.6 \%$ & $2.2 \%$ & $1.1 \%$ & $8.8 \%$ \\
\hline Western & $19.2 \%$ & $2.0 \%$ & $3.3 \%$ & $20.5 \%$ & $26.4 \%$ & $2.8 \%$ & $3.4 \%$ & $27.6 \%$ & $8.0 \%$ & $1.3 \%$ & $4.1 \%$ & $10.1 \%$ \\
\hline Deprivation indicator & $p=0.416$ & $p=0.003^{S}$ & $p=0.071$ & $p=0.292$ & $p=0.542$ & $p=0.026$ & $p=0.243$ & $p=0.531$ & $p=0.886$ & $p=0.154$ & $p=0.687$ & $p=0.865$ \\
\hline Least deprived & $15.9 \%$ & $1.9 \%$ & $2.8 \%$ & $16.7 \%$ & $25.3 \%$ & $4.1 \%$ & $4.2 \%$ & $25.9 \%$ & $5.9 \%$ & $0.4 \%$ & $1.1 \%$ & $6.6 \%$ \\
\hline Quintile 2 & $18.7 \%$ & $3.3 \%$ & $3.0 \%$ & $19.2 \%$ & $24.5 \%$ & $3.3 \%$ & $2.7 \%$ & $24.7 \%$ & $6.7 \%$ & $2.2 \%$ & $1.8 \%$ & $7.4 \%$ \\
\hline Quintile 3 & $18.7 \%$ & $3.5 \%$ & $2.6 \%$ & $19.8 \%$ & $26.5 \%$ & $6.7 \%$ & $3.1 \%$ & $28.0 \%$ & $7.1 \%$ & $2.2 \%$ & $2.2 \%$ & $8.0 \%$ \\
\hline Quintile 4 & $16.6 \%$ & $1.0 \%$ & $2.1 \%$ & $18.0 \%$ & $21.0 \%$ & $1.1 \%$ & $2.4 \%$ & $22.2 \%$ & $7.0 \%$ & $0.7 \%$ & $0.5 \%$ & $7.6 \%$ \\
\hline Most deprived & $20.3 \%$ & $5.3 \%$ & $5.4 \%$ & $22.1 \%$ & $27.3 \%$ & $6.8 \%$ & $5.9 \%$ & $28.7 \%$ & $8.5 \%$ & $0.0 \%$ & $2.0 \%$ & $10.0 \%$ \\
\hline Urban/rural indicator & $p=0.037$ & $p=0.523$ & $p=0.216$ & $p=0.059$ & $p=0.030$ & $p=0.293$ & $p=0.124$ & $p=0.051$ & $p=0.769$ & $p=0.138$ & $p=0.684$ & $p=0.563$ \\
\hline Urban & $19.2 \%$ & $3.1 \%$ & $3.4 \%$ & $20.2 \%$ & $27.0 \%$ & $4.9 \%$ & $4.3 \%$ & $27.8 \%$ & $6.7 \%$ & $0.7 \%$ & $1.3 \%$ & $7.3 \%$ \\
\hline Rural & $15.8 \%$ & $2.6 \%$ & $2.5 \%$ & $17.0 \%$ & $20.9 \%$ & $3.4 \%$ & $2.5 \%$ & $22.3 \%$ & $7.2 \%$ & $1.8 \%$ & $1.7 \%$ & $8.4 \%$ \\
\hline Marital status* & $p<0.001^{s}$ & $p=0.149$ & $p=0.551$ & $p<0.001^{s}$ & $p<0.001^{s}$ & $p=0.108$ & $p=0.771$ & $p<0.001^{s}$ & $p=0.004^{s}$ & $p=0.476$ & $p=0.390$ & $p=0.009$ \\
\hline Married & $18.1 \%$ & $2.9 \%$ & $3.3 \%$ & $19.1 \%$ & $25.8 \%$ & $4.2 \%$ & $4.0 \%$ & $26.8 \%$ & $6.5 \%$ & $1.0 \%$ & $1.6 \%$ & $7.4 \%$ \\
\hline Separated/Divorced & $27.6 \%$ & $4.7 \%$ & $3.6 \%$ & $28.7 \%$ & $37.6 \%$ & $8.4 \%$ & $4.7 \%$ & $39.2 \%$ & $15.9 \%$ & $2.9 \%$ & $2.8 \%$ & $15.9 \%$ \\
\hline Widowed & $13.4 \%$ & $2.9 \%$ & $1.9 \%$ & $14.4 \%$ & $12.8 \%$ & $3.1 \%$ & $2.4 \%$ & $14.3 \%$ & $9.9 \%$ & $1.4 \%$ & $0.0 \%$ & $10.2 \%$ \\
\hline Single & $6.7 \%$ & $0.8 \%$ & $1.5 \%$ & $7.5 \%$ & $11.3 \%$ & $0.0 \%$ & $1.6 \%$ & $11.5 \%$ & $0.0 \%$ & $0.0 \%$ & $0.0 \%$ & $0.0 \%$ \\
\hline
\end{tabular}




\begin{tabular}{|c|c|c|c|c|c|c|c|c|c|c|c|c|}
\hline $\begin{array}{l}\text { Number of long-term } \\
\text { conditions }\end{array}$ & $p<0.001^{s}$ & $p=0.005^{s}$ & $p=0.008$ & $p<0.001^{s}$ & $p=0.052$ & $p=0.391$ & $p=0.507$ & $p=0.030$ & $p=0.272$ & $p=0.711$ & $p=0.540$ & $p=0.375$ \\
\hline No conditions & $11.5 \%$ & $1.4 \%$ & $1.3 \%$ & $11.9 \%$ & $18.3 \%$ & $3.6 \%$ & $2.5 \%$ & $18.4 \%$ & $5.5 \%$ & $0.8 \%$ & $1.2 \%$ & $6.2 \%$ \\
\hline $1-2$ conditions & $19.0 \%$ & $3.1 \%$ & $3.7 \%$ & $20.4 \%$ & $25.4 \%$ & $3.8 \%$ & $3.5 \%$ & $26.8 \%$ & $7.4 \%$ & $1.3 \%$ & $1.9 \%$ & $8.4 \%$ \\
\hline 3 or more conditions & $24.2 \%$ & $4.7 \%$ & $4.1 \%$ & $25.6 \%$ & $27.6 \%$ & $5.7 \%$ & $4.6 \%$ & $28.5 \%$ & $9.4 \%$ & $1.6 \%$ & $0.8 \%$ & $9.6 \%$ \\
\hline Body Mass Index (BMI) & $p=0.001^{\mathrm{s}}$ & $p=0.045$ & $p=0.087$ & $p=0.001^{\mathrm{s}}$ & $p=0.319$ & $p=0.378$ & $p=0.433$ & $p=0.386$ & $p=0.020$ & $p=0.347$ & $p=0.892$ & $p=0.047$ \\
\hline Under \& healthy weight $(0-25)$ & $13.7 \%$ & $1.4 \%$ & $1.8 \%$ & $14.5 \%$ & $22.4 \%$ & $2.8 \%$ & $2.4 \%$ & $23.4 \%$ & $3.9 \%$ & $0.4 \%$ & $1.2 \%$ & $4.8 \%$ \\
\hline Overweight $(25-30)$ & $20.0 \%$ & $3.1 \%$ & $3.2 \%$ & $20.8 \%$ & $27.5 \%$ & $4.8 \%$ & $4.3 \%$ & $28.2 \%$ & $8.4 \%$ & $1.5 \%$ & $1.4 \%$ & $8.8 \%$ \\
\hline Obese $(30+)$ & $21.1 \%$ & $3.7 \%$ & $3.9 \%$ & $23.0 \%$ & $25.8 \%$ & $4.6 \%$ & $4.1 \%$ & $27.6 \%$ & $10.1 \%$ & $1.6 \%$ & $1.3 \%$ & $10.9 \%$ \\
\hline Self-assessed health score & $p=0.124$ & $p<0.001^{s}$ & $p=0.032$ & $p=0.056$ & $p=0.968$ & $p=0.007$ & $p=0.029$ & $p=0.964$ & $p=0.143$ & $p=0.931$ & $p=0.412$ & $p=0.182$ \\
\hline 90 and over (better health) & $16.2 \%$ & $2.2 \%$ & $2.3 \%$ & $17.3 \%$ & $25.9 \%$ & $3.6 \%$ & $1.4 \%$ & $26.4 \%$ & $6.6 \%$ & $1.2 \%$ & $2.0 \%$ & $7.9 \%$ \\
\hline $80-89.9$ & $16.7 \%$ & $1.2 \%$ & $2.2 \%$ & $16.9 \%$ & $24.2 \%$ & $0.9 \%$ & $2.3 \%$ & $24.5 \%$ & $6.3 \%$ & $0.9 \%$ & $0.9 \%$ & $6.7 \%$ \\
\hline $70-79.9$ & $19.8 \%$ & $3.1 \%$ & $3.5 \%$ & $21.0 \%$ & $24.3 \%$ & $4.5 \%$ & $5.5 \%$ & $26.0 \%$ & $11.7 \%$ & $1.6 \%$ & $1.5 \%$ & $11.8 \%$ \\
\hline Under 70 (poorer health) & $20.7 \%$ & $5.5 \%$ & $4.9 \%$ & $22.3 \%$ & $24.9 \%$ & $6.7 \%$ & $5.2 \%$ & $26.2 \%$ & $4.4 \%$ & $0.7 \%$ & $0.0 \%$ & $4.4 \%$ \\
\hline
\end{tabular}

Notes:

Data are weighted to the NI population by age and deprivation.

Breakdown by self-reported erectile/sexual dysfunction excludes respondents who did not answer that question.

$p$-value is the result of chi-square test for variation in the proportion reporting offer of services for that variable. "S" denotes variation is significant at a 95\% significance level after

Bonferonni correction for multiple comparisons

* Includes civil partnership equivalents. 
Table 3: Proportion of men aged 60 and over offered treatment to aid or improve erections by extent of interest in sex and sexual activity (EORTC-PR25)

\begin{tabular}{|c|c|c|c|c|c|c|c|c|c|c|c|c|}
\hline & \multicolumn{4}{|c|}{$\begin{array}{l}\text { Proportion of men aged } 60 \text { and over who had been } \\
\text { offered service to improve erections }\end{array}$} & \multicolumn{4}{|c|}{$\begin{array}{c}\text { Proportion of men aged } 60 \text { and over currently reporting } \\
\text { erectile dysfunction who had been offered service to } \\
\text { improve erections }\end{array}$} & \multicolumn{4}{|c|}{$\begin{array}{c}\text { Proportion of men aged } 60 \text { and over currently reporting no } \\
\text { problems with sexual function who had been offered service } \\
\text { to improve erections }\end{array}$} \\
\hline & $\begin{array}{l}\text { Medications } \\
(\mathrm{n}=2,331)\end{array}$ & $\begin{array}{l}\text { Devices or } \\
\quad \text { aids } \\
(\mathrm{n}=2,312)\end{array}$ & $\begin{array}{l}\text { Specialised } \\
\text { services } \\
(\mathrm{n}=2,307)\end{array}$ & $\begin{array}{l}\text { Any service } \\
(\mathrm{n}=2,324)\end{array}$ & $\begin{array}{l}\text { Medications } \\
(n=1,059)\end{array}$ & $\begin{array}{l}\text { Devices or } \\
\quad \text { aids } \\
(\mathrm{n}=1,053)\end{array}$ & $\begin{array}{l}\text { Specialised } \\
\text { services } \\
(n=1,044)\end{array}$ & $\begin{array}{l}\text { Any service } \\
(n=1,054)\end{array}$ & $\begin{array}{l}\text { Medications } \\
(\mathrm{n}=921)\end{array}$ & $\begin{array}{l}\text { Devices or } \\
\text { aids } \\
(n=918)\end{array}$ & $\begin{array}{l}\text { Specialised } \\
\text { services } \\
(\mathrm{n}=917)\end{array}$ & $\begin{array}{c}\text { Any service } \\
(\mathrm{n}=918)\end{array}$ \\
\hline All respondents & $18.0 \%$ & $2.9 \%$ & $3.1 \%$ & $19.1 \%$ & $24.8 \%$ & $4.4 \%$ & $3.6 \%$ & $25.8 \%$ & $6.9 \%$ & $1.1 \%$ & $1.5 \%$ & $7.7 \%$ \\
\hline $\begin{array}{l}\text { Extent of } \\
\text { interest in sex }\end{array}$ & $p=0.002^{s}$ & $p=0.002^{s}$ & $p<0.001^{s}$ & $p=0.008^{s}$ & $p<0.001^{s}$ & $p=0.027$ & $p=0.186$ & $p<0.001^{s}$ & $p=0.110$ & $p=0.482$ & $p=0.005$ & $p=0.485$ \\
\hline Not at all & $15.1 \%$ & $5.3 \%$ & $6.4 \%$ & $17.7 \%$ & $16.9 \%$ & $5.5 \%$ & $5.2 \%$ & $18.2 \%$ & $3.1 \%$ & $1.7 \%$ & $4.0 \%$ & $5.9 \%$ \\
\hline A little & $15.5 \%$ & $2.0 \%$ & $2.1 \%$ & $16.1 \%$ & $21.0 \%$ & $2.3 \%$ & $2.6 \%$ & $21.8 \%$ & $6.9 \%$ & $<5$ & $0.0 \%$ & $7.0 \%$ \\
\hline $\begin{array}{l}\text { Quite a bit/ } \\
\text { very much }\end{array}$ & $21.0 \%$ & $2.5 \%$ & $2.3 \%$ & $21.6 \%$ & $41.0 \%$ & $5.8 \%$ & $3.3 \%$ & $42.0 \%$ & $7.9 \%$ & $1.3 \%$ & $1.5 \%$ & $8.6 \%$ \\
\hline $\begin{array}{l}\text { Extent of sexual } \\
\text { activity }\end{array}$ & $p=0.981$ & $p=0.796$ & $p=0.090$ & $p=0.928$ & $p<0.001^{s}$ & $p=0.060$ & $p=0.018^{s}$ & $p<0.001^{s}$ & $p=0.161$ & $p=0.655$ & $p=0.084$ & $p=0.397$ \\
\hline Not at all & $18.1 \%$ & $3.0 \%$ & $3.8 \%$ & $19.5 \%$ & $21.2 \%$ & $3.5 \%$ & $3.8 \%$ & $22.2 \%$ & $4.2 \%$ & $1.2 \%$ & $2.7 \%$ & $6.2 \%$ \\
\hline A little & $18.4 \%$ & $2.5 \%$ & $2.0 \%$ & $18.9 \%$ & $27.5 \%$ & $3.5 \%$ & $2.2 \%$ & $27.9 \%$ & $7.3 \%$ & $0.7 \%$ & $<5$ & $7.4 \%$ \\
\hline $\begin{array}{l}\text { Quite a bit/ } \\
\text { very much }\end{array}$ & $18.3 \%$ & $2.5 \%$ & $3.2 \%$ & $19.1 \%$ & $43.5 \%$ & $8.4 \%$ & $9.0 \%$ & $45.8 \%$ & $8.6 \%$ & $1.5 \%$ & $1.6 \%$ & $9.2 \%$ \\
\hline
\end{tabular}

Notes:

Data are weighted to the NI population by age and deprivation.

Breakdown by self-reported erectile/sexual dysfunction excludes respondents who did not answer that question.

$p$-value is the result of chi-square test for variation in the proportion reporting offer of services for that variable. "S" denotes variation is significant at a $95 \%$ significance level after Bonferonni correction for multiple comparisons

" $<5$ " refers to less than 5 respondents. Exact figure is suppressed to ensure respondent confidentiality. Significance tests are however conducted using the actual number of responses.

* Includes civil partnership equivalents. 
Table 4: Odds ratios for offer of either medications, devices or specialised services to aid or improve erections

\begin{tabular}{|c|c|c|c|c|c|c|c|c|c|}
\hline & \multicolumn{3}{|c|}{ All men aged 60 and over } & \multicolumn{3}{|c|}{$\begin{array}{l}\text { Men aged } 60 \text { and over currently reporting } \\
\text { erectile dysfunction }\end{array}$} & \multicolumn{3}{|c|}{$\begin{array}{l}\text { Men aged } 60 \text { and over currently reporting no } \\
\text { problems with sexual function }\end{array}$} \\
\hline & Odds ratio & $\begin{array}{c}95 \% \\
\text { confidence } \\
\text { interval }\end{array}$ & $p$-value & Odds ratio & $\begin{array}{c}95 \% \\
\text { confidence } \\
\text { interval }\end{array}$ & p-value & Odds ratio & $\begin{array}{c}95 \% \\
\text { confidence } \\
\text { interval }\end{array}$ & p-value \\
\hline \multicolumn{10}{|l|}{ Age group } \\
\hline $60-69$ & 1.00 & & & 1.00 & & & 1.00 & & \\
\hline $70-79$ & 1.08 & $(0.83,1.39)$ & $p=0.580$ & 0.97 & $(0.70,1.34)$ & $p=0.853$ & 1.30 & $(0.74,2.27)$ & $p=0.360$ \\
\hline $80+$ & 0.40 & $(0.25,0.65)$ & $p<0.001$ & 0.28 & $(0.16,0.47)$ & $\mathrm{p}<0.001$ & 0.23 & $(0.04,1.31)$ & $p=0.098$ \\
\hline \multicolumn{10}{|l|}{ Marital status* } \\
\hline Married & 1.00 & & & 1.00 & & & 1.00 & & \\
\hline Separated/Divorced & 1.62 & $(1.13,2.33)$ & $p=0.009$ & 1.53 & $(0.95,2.47)$ & $p=0.080$ & 2.44 & $(1.19,4.97)$ & $p=0.014$ \\
\hline Widowed & 0.79 & $(0.49,1.28)$ & $p=0.343$ & 0.71 & $(0.39,1.28)$ & $p=0.253$ & 1.58 & $(0.64,3.94)$ & $p=0.323$ \\
\hline Single & 0.40 & $(0.20,0.81)$ & $p=0.011$ & 0.37 & $(0.16,0.89)$ & $p=0.026$ & \multicolumn{3}{|c|}{ No respondents } \\
\hline \multicolumn{10}{|c|}{ Number of long-term conditions } \\
\hline No conditions & 1.00 & & & 1.00 & & & 1.00 & & \\
\hline $1-2$ conditions & 1.65 & $(1.20,2.27)$ & $p=0.002$ & 1.60 & $(1.02,2.50)$ & $p=0.039$ & 1.70 & $(0.91,3.16)$ & $p=0.096$ \\
\hline $3+$ conditions & 1.75 & $(1.20,2.55)$ & $p=0.004$ & 1.72 & $(1.07,2.77)$ & $p=0.026$ & 2.35 & $(1.00,5.52)$ & $p=0.050$ \\
\hline \multicolumn{10}{|l|}{ Body Mass Index (BMI) } \\
\hline Under \& healthy weight $(0-25)$ & 1.00 & & & \multicolumn{3}{|c|}{ Not significant } & 1.00 & & \\
\hline Overweight $(25-30)$ & 1.36 & $(1.02,1.81)$ & $p=0.037$ & & & & 1.92 & $(0.99,3.73)$ & $p=0.054$ \\
\hline Obese $(30+)$ & 1.27 & $(0.90,1.79)$ & $p=0.171$ & & & & 2.28 & $(1.02,5.08)$ & $p=0.044$ \\
\hline \multicolumn{10}{|l|}{ Extent of interest in sex } \\
\hline Not at all & 1.00 & & & 1.00 & & & \multicolumn{3}{|c|}{ Not significant } \\
\hline A little & 1.12 & $(0.78,1.60)$ & $p=0.532$ & 1.13 & $(0.78,1.65)$ & $p=0.518$ & & & \\
\hline Quite a bit/Very much & 2.15 & $(1.49,3.10)$ & $p<0.001$ & 2.67 & $(1.79,3.97)$ & $p<0.001$ & & & \\
\hline \multicolumn{10}{|l|}{ Erectile dysfunction } \\
\hline No & 1.00 & & & - & - & - & - & - & - \\
\hline Yes & 3.26 & $(2.47,4.29)$ & $p<0.001$ & - & - & - & - & - & - \\
\hline
\end{tabular}

Data are weighted to the NI population by age and deprivation.

Results adjusted for other significant variables in table. 


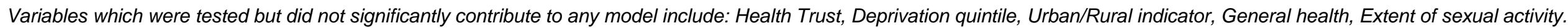
Erectile dysfunction only included as a possible covariate for all men.

* Includes civil partnership equivalents. 
Figure 1: Men aged 60 and over offered treatment to aid or improve erections over the last three years

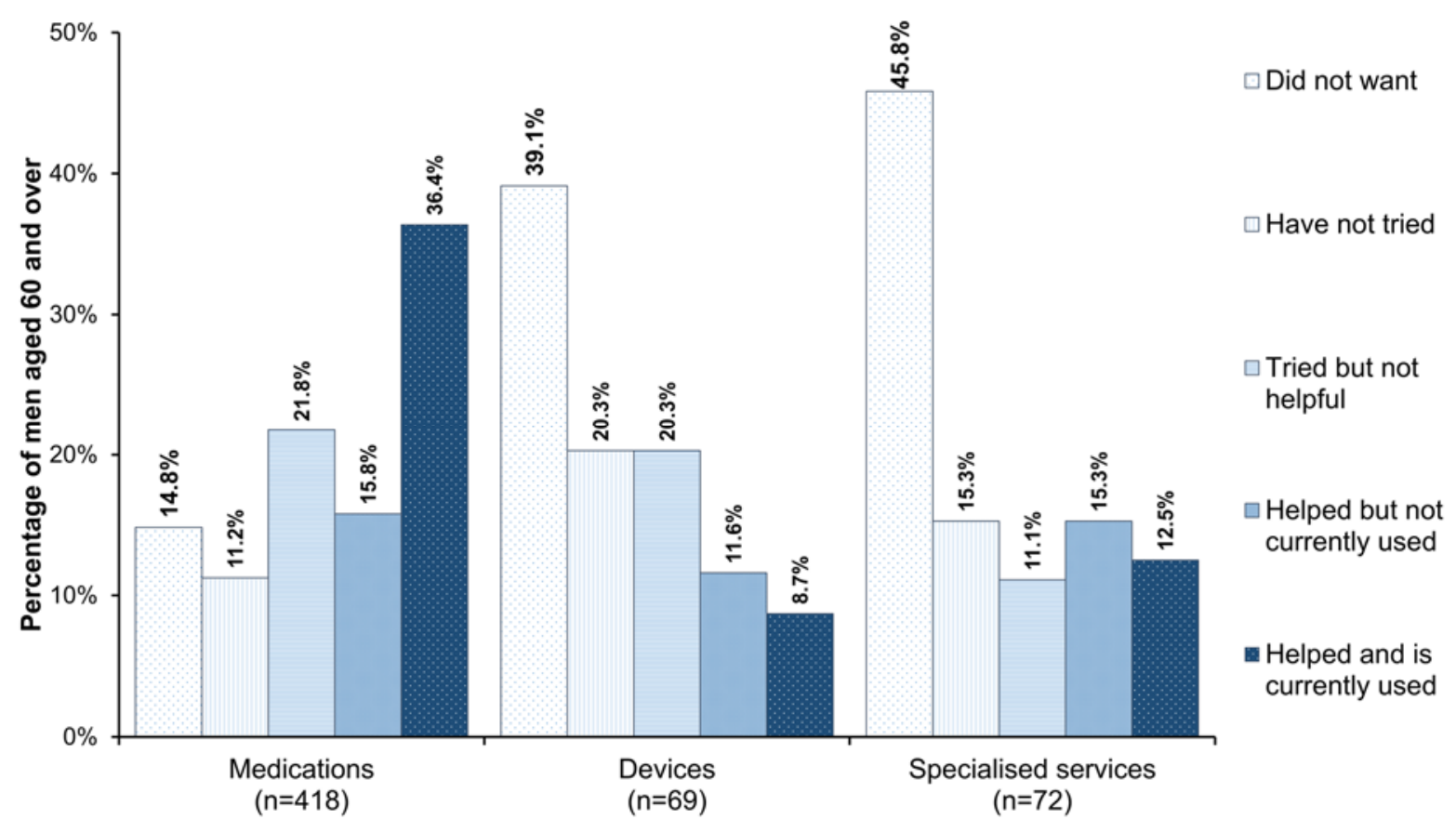

Notes:

Data are weighted to the NI population by age and deprivation. 
Figure 2: Men currently reporting erectile dysfunction and no problems with sexual function offered medication to aid or improve erections over the last three years

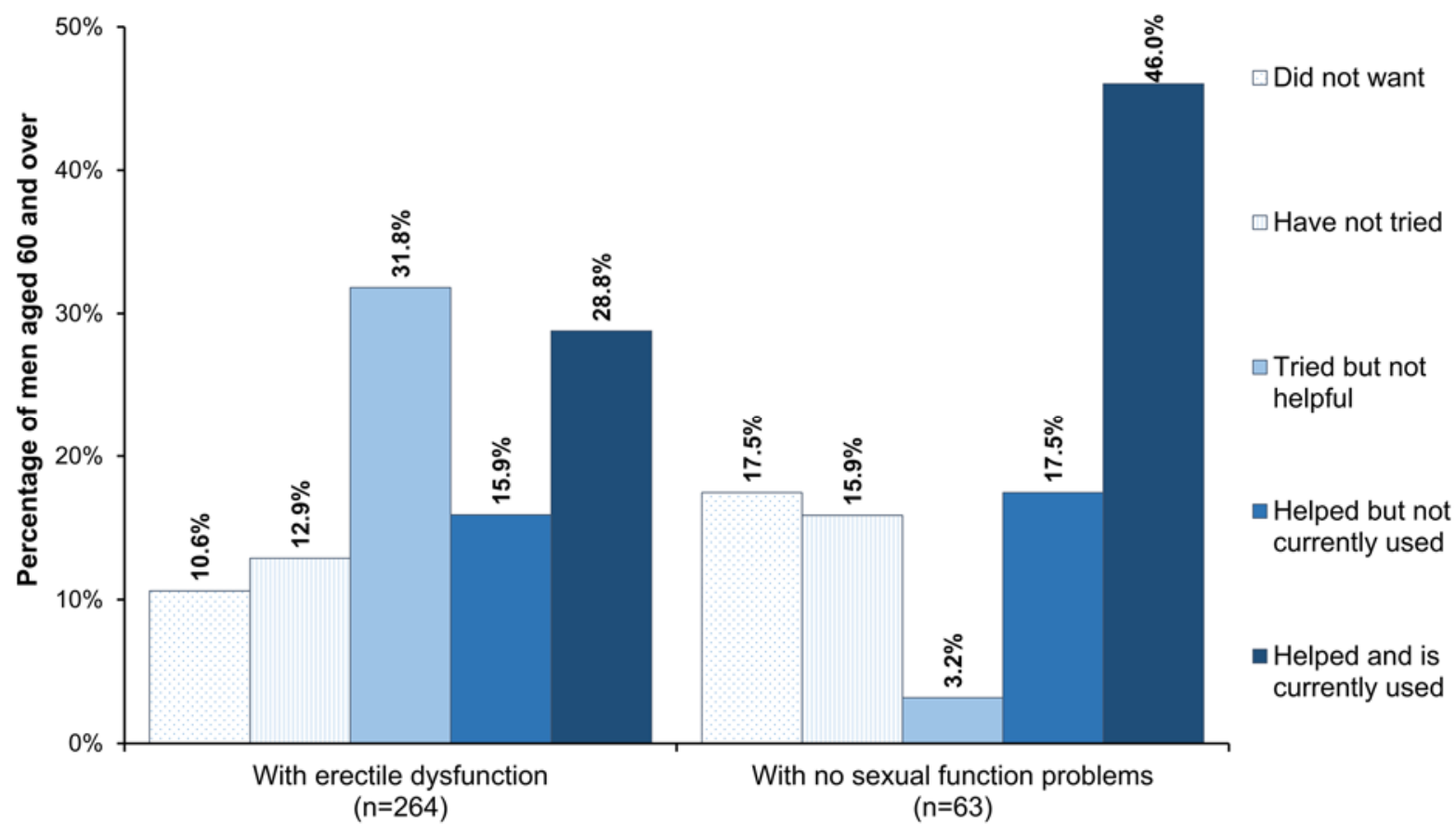

Notes:

Data are weighted to the NI population by age and deprivation. 